\title{
Case Report of Long Lasting Seroma, its Infection with Staphylococcus Aureus, After Medial Thigh Lift with Concomitant Liposuction
}

\section{Žikla I*}

Plastic surgeon in ŽIKLA s.r.o., Private Esthetic Surgery, Slovakia

*Corresponding author: Žikla I, Plastic surgeon in ŽIKLA s.r.o., Private Esthetic Surgery, Banská Bystrica, Slovakia, ivan@zikla.sk

\section{Case Report \\ Volume 4 Issue 1}

Received Date: April 22, 2020

Published Date: June 01, 2020

DOI: $10.23880 /$ ijtps-16000145

\section{Abstract}

Background: Seroma and wound healing problems are the most common complications following medial thigh lift and liposuction in massive weight loss patients.

Methods: Author describes a case report of his patient and his treatment strategy.

Results: The patient underwent two surgeries of medial thigh lift with long lasting seroma after operations which were infected afterwards by Staphylococcus aureus from her focus in her nasal cavity.

Conclusion: In massive weight loss patient the medial thigh lift is a very desirable procedure which is safe, quick with quite good results despite the risk of complications. The focus infection theory has to be considered in any types of procedures.

Keywords: Seroma; Medial thigh lift; Liposuction; Complication; Focus Infection

\section{Introduction}

The number of massive weight loss patients is still rising up. It doesn't matter if the loss was the result of bariatric surgery or strict diet and physical examination. The patients stay satisfied with their weight but unsatisfied with their body image. The laxity of skin can cause functional impairment, recurrent skin infections, as well as considerable psychological discomfort [1].

After the correction of breasts, abdomen, arms and buttock, takes place the correction of medial thighs.

We have a lot of techniques how to reshape the massive weight loss body. Very nice history of these procedures described colleagues from Italy and Albania [1].

\section{Horizontal Thigh Lift}

This procedure is ideal for minimal skin laxity of proximal thighs. The incision is made in the inguinal fold up to the infragluteal crease. The tissue undermining to the muscle fascia and reliable deep stitches are needed for the good result. Other alternative is to use liposuction to undermine the skin.

The disadvantage is lowering the scar in the ingiuna and inadequate result.

\section{Vertical Thigh Lift}

Very good technique for improvement of inner thighs. The incision is made on the whole medial thigh a few centimeters below the major labia up to the knee. The scar is situated not to be seen in straight standing position. We have two possibilities how to perform it. First is to respect the whole mass of tissue to the muscular fascia en block and second is to use liposuction to remove the fat by preserving the vessels and nerves. This technique brings very good results for massive weight loss patients.

"L" - shaped scar or "T" - shaped scar medial thigh lift.

This is the combination of both - horizontal and vertical. 


\section{International Journal of Transplantation \& Plastic Surgery}

If we use "L" or "T" shaped scar technique depends on each patient.

All massive weight loss patients are not healthy patients. They suffer from malnutrition, low proteins, hypovitaminosis and are prone to healing complications. The complication rate of $42,72 \%$, among which the most frequent were the wound dehiscence $(18,34)$ and the seroma $(8,05 \%)$ described Sisti, et al. [2].

\section{Case Report}

I report a case of 35 years old woman, non-smoker, weight loss $48 \mathrm{~kg}$ with BMI 28,7.

She underwent abdominoplasty 3 years ago and mastopexy 2 years ago in different practices. After the mastopexy, there was a healing problem of nipples in the way of partial necrosis. The abdominoplasty was without any healing problems but the "dog ears" at both ends of the horizontal suture.

When I saw her first time I decided to perform an avulsion vertical medial thigh lift with liposuction sec. Hunstad with concomitant liposuction of the hips and frontal and lateral thighs, lower abdomen and flanks and correction of "dog ears" after abdominoplasty.

The result of pre-operative physical examinations were without any abnormal values. One week before the surgery she took pills with combination of Rutin $20 \mathrm{mg}$ and L-ascorbic acid $100 \mathrm{mg}$ because of their benefit to capillary vessels. Before the surgery were taken photos. The preop planning was in upright position.

During the surgery I used avulsion technique to reduce the preplanned amount of skin. The closure was made in two layers with poliglecapron 25 3-0 and 5-0 and the intradermal suture with polyglactin $9104-0.4000 \mathrm{ml}$ of fat was suctioned altogether. No complications occurred during the surgery. All closures were covered with steri-strips and compression garment was put on. No suction drains were used.

\section{Here is the Chronological List of the Visits:}

10 days - afebrile, two small dehiscences in the scar without secretion on the left medial thigh scar, without cellulitis, no fluctuation, prescribed oral Cefuroxim $500 \mathrm{mg}$ á 12 hours to reduce the risk of secondary infection.

4 weeks - 7 days subfebrile, GP's prescription of Amoxicillin with beta lactamase inhibitor $1000 \mathrm{mg}$ á 12 hours, on the left medial thigh scar three small dehiscences, fluctuation on the distal LATERAL left thigh where was no scar but liposuction performed, punction of $30 \mathrm{ml}$ clear seroma, compression.

8 weeks - subfebrile, pain, erythema, fluctuation, edema of the distal lateral left thigh with $75 \mathrm{ml}$ seroma. Seroma send to microbiology with the conclusion - sterile, injection of $1 \mathrm{ml}$ of glucocorticoid Betamethasone into the cavity, oral Cefuroxim 500 mg á 12 hours, compression, the medial scars were completely healed.

9 - 10 weeks - still subfebrile, pain, fluctuation, edema, phlegmona, excoriation of the distal lateral left thigh, CRP 18,3 .

Punction of $75 \mathrm{ml}$ and $50 \mathrm{ml}$ of pus during two days, microbiology with the conclusion Staphylococcus aureus, lavage with Hydrogen peroxide $3 \%$ and povidone iodine, prescribed oral Clindamycine 300 mg á 12 hours.

USG described phlegmona with abscess $10 \mathrm{~cm}$ and inguinal lymphadenopathy.

We prepared the patient for the revision operation where I found no abscess and clear seroma of $20 \mathrm{ml}$ what was surprisingly good finding. I put suction drain for three days which collected $60 \mathrm{ml}$ of clear seroma and compression to minimalise the death space.

11 weeks after first operation and 1 week after revision - afebrile, no edema, no erythema, no fluctuation, oral Clindamycine 300 mg á 12 hours for one week more.

17 weeks after first operation and 7 weeks after revision - afebrile, all wounds healed.

On my recommendation she underwent a dental, ORL, gynecological and imunological examination to look for any focuses. She was found Staphylococcus aureus in her nose cavity and her daughter too.

She was unsatisfied with the result, visited me with complaint and want to correct the medial parts of knees where she had redundant tissue and in the crotch as well 5 months after.

I decided to follow the medial thigh incision to the middle third of the shin with the resection of redundant tissue and to perform a horizontal thigh lift with correction liposuction of hips with one condition and there was to repeat the focus examination of her nasal cavity.

The results were negative, so I did the correction as I mentioned above. The first check on $11^{\text {th }}$ day was without any problem. 


\section{International Journal of Transplantation \& Plastic Surgery}

3 weeks - afebrile, small fluctuation on the left medial knee, no inflammation, punction of $5 \mathrm{ml}$ clear seroma, compression on the knee, other scars were without any problem.

5 weeks - afebrile, a small dehiscence of the scar on the left medial knee with secretion, no inflammation.

6 weeks - afebrile, two dehiscences of $2 \mathrm{~cm}$ and $4 \mathrm{~cm}$ with secretion, no inflammation, lavage with Hydrogen peroxide $3 \%$ and povidone iodine, microbiology conclusion Staphylococcus aureus, prescribed Cefuroxim 500 mg á 12 hours p.o., and injected $1 \mathrm{ml}$ of glucocorticoid Betamethasone into the cavity, compression.

7 weeks - afebrile, dehiscences were healed, fluctuation persists, no inflammation, punction of $10 \mathrm{ml}$ clear seroma, lavage with Hydrogen peroxide $3 \%$ and povidone iodine, injected $1 \mathrm{ml}$ of glucocorticoid Betamethasone into the cavity, compression.

11 weeks - afebrile, still seroma secretion from the left medial knee, no inflammation, compression, but new inflammation of the right medial knee, wit no fluctuation, prescribed Cefuroxim 500 mg á 12 hours p.o.

12 weeks - afebrile, little seroma secretion from the left medial knee and no inflammation and no fluctuation on the right knee.

13 weeks - the process has stopped with the conservative therapy and she is planning the brachioplasty in the future.

\section{Discussion}

Obesity is a rapidly growing disease that has spread widely in the western world and presents as an emerging issue in developing countries. The increase of the obese population has popularized the demand for bariatric surgery, and it is estimated that more than $70 \%$ of the patients who undergo such surgery state that, due to skin laxity and ptosis of certain anatomical areas, significant weight loss causes an unacceptable worsening of their body image. This becomes more relevant in our beauty- centered global society, where life is fast-paced and people are rapidly judged with regards to their appearance. It has therefore become more common for the patient who has undergone a great amount of weight reduction to present to the plastic surgeon requesting the removal of excess skin, from one or, more typically, many regions of the body. This wrote Ivo Pitanguy as Foreword to Aesthetic Surgery after Massive Weight Loss by Rubin and Matarasso [3].

There was performed total $1,811,740$ cosmetic surgical procedures in the USA in 2018. The Thigh lift underwent 10,100 patients. $95 \%$ were women and mostly aged between 40 and $54(4,771)[4]$. So we can say that this procedure is not so often compared to other procedures like Upper arm lift $(17,338)$, Abdominoplasty $(130,081)$, Liposuction $(258,558)$ but not at the end compared to Lower body lift $(9,098)$ and Buttock lift $(4,824)$ from these body contour procedures after weight loss [4].

Aboueldahab AK described 25 patients without necrosis, seroma, labial distortion or separation in patients with liposuction-assisted medial thigh lift [5].

After L-shaped lipothighplasty, 3 patients (19\%) from 16 had complications in the postoperative period. No skin necrosis, hematoma, seroma, or thromboembolic events were reported. Two patients experienced hypertophic scarring and 1 patient had a wound infection because of poor hygienic care presented Bracaglia $R$, et al. [6].

Complication after ' $\mathrm{T}$ ' scar technique and concomitant liposuction examined Simone P, et al. in 46 postbariatric female patients. They did not observe major systemic complications, haematoma, seroma, infection, skin necrosis, lymphoceles, or lymphoedema. Minor complications were three cases of wound dehiscence and two cases of deepithelialisation. At the 1-year follow-up visit, caudal scar migration, genital distortion, recurrent ptosis, or deformity of the inner thigh contour were not observed [7].

In bigger studies we can see more complication risk like e.g. Capella and Matarasso published the overall complication rate of 350 patients who had undergone vertical medial thigh lift which was $45.14 \%$. The most frequent complications were skin dehiscence (31.14\%) and seroma (18.18\%) [8].

Shermak, et al. described seroma formation following body contouring surgery in 222 patients. Seroma occurred in $14 \%$ of patients and the most important risk factor was the weight of skin excised at the time of surgery increasing 9 $\%$ for each additional pound [9].

After these studies we can say that the risk of seroma is relatively high, about $16 \%$.

There was very little information about infection in these studies.

Dehiscence of the skin can be infected secondary because the dehiscence is mainly the result of necrosis. But we can see an infection of seroma too.

In Merriam-Webster dictionary we can find a noun focal infection. The definition is: a persistent bacterial infection 


\section{International Journal of Transplantation \& Plastic Surgery}

of some organ or region; especially: one causing symptoms elsewhere in the body [10].

In 1940, Reimann and Havens, published: The concept of focal infection in relation to systemic disease is firmly established. The origin of many toxic or metastatic diseases may be traced to primary local or focal areas of infection. As examples, gonorrhea and gonococcic arthritis, furuncles and septicemia, tetanus and other self-limiting diseases may be cited. It is not surprising, therefore, that a similar relationship is thought to exist between various general systemic diseases of unknown origin and infections of the teeth, tonsils, nasal sinuses, appendix, gallbladder and cervix and infections elsewhere [11].

Post liposuction infections are by literature most often caused by Mycobacterium or Streptoccocus [12-15].

Staphylococcus aureus can cause even a Toxic shock syndrome, what is potentially life-threatening condition resulting from its exotoxin [16].

\section{Conclusion}

My case report is interesting in that way that postoperative process was normal until the seroma occurred about three weeks after both operations.

After the first operation seroma occurred in a region post liposuction and for 8 weeks was the result of microbiology sterile. Then the seroma was infected with Staphylococcus aureus and the patient needed revision operation, when the problem was solved. Interesting is, that the origin of infection was in her nasal cavity and did not achieved the post medial thigh lift wound for the whole recovery time.

Before the second procedure she underwent the same screenings to exclude the Staphylococcus infection and they were all negative.

Despite these negative results, the same situation happened. About three weeks after occurred sterile seroma and in the sixth week was infected with Staphylococcus aureus.

It seems, that the focus infection theory is worthy in her case because we did not find any origin of her infection.

The seroma was treated with punction, local glucocorticoids, compression and finally revision. I used suction drains after the revision surgery for three days and compression to minimalise the death space. The infection was treated with oral antibiotics.
In my opinion the avulsion technique of vertical medial thigh lift is very effective and safe procedure, even with the concomitant liposuction. But on the other hand I see best results in non-massive weight loss patients because it leaves residual tissue (dog ears) in the crotch and my patient complain about it. In these massive weight loss patients I prefer the "L" or the "T" scar technique.

\section{References}

1. Verdiana Di P, Marcello CG, Valerio C, Pietro G (2019) Medial Thigh Contouring in Massive Weight Loss: A Liposuction-Assisted Medial Thigh Lift. World J Plast Surg 8(2): 171-180.

2. Sisti A, Cuomo R, Zerini I, Tassinari J, Brandi C, et al. (2015) Complications Associated With Medial Thigh Lift: A Comprehensive Literature Review. J Cutan Aesthet Surg 8(4): 191-197.

3. Rubin JP, Matarasso A (2007) Aesthetic Surgery aferer Massive Weight Loss. Saunders Elsevier.

4. Plastic Surgery Statistics Report

5. Aboueldahab AK (2013) Liposuction-assisted medial thigh lift in obese and non obese patients. J Cutan Aesthet Surg 6(4): 217-225.

6. Bracaglia R, Tambasco D, Gentileschi S, D’Ettorre M (2015) L-Shaped Lipothighplasty. Ann Plast Surg 75(3): 261-265.

7. Simone P, Carusi C, Del Buono R, Persichetti P (2016) Medial Thigh Lift in Post-Bariatric Patients: Our Encouraging Experience. J Plast Surg Hand Surg 50(6): 359-366.

8. Capella JF, Matarasso A (2016) Management of the Postbariatric Medial Thigh Deformity. Plast Reconstr Surg 137(5): 1434-1446.

9. Shermak MA, Rotellini-Coltvet LA, Chang D (2008) Seroma development following body contouring surgery for massive weight loss: patient risk factors and treatment strategies. Plast Reconstr Surg 122(1): 280288.

10. Focal Infection. Merriam Webster

11. Hobart A Reinmann, Paul Havens W (1940) Focal infection and systemic disease: A critical appraisal. JAMA 114(1): 1-6.

12. Hui SH, Noonan L, Chavada R (2015) Post Liposuction Mycobacterium Abscessus Surgical Site Infection in a Returned Medical tourist Complicated by a Paradoxical 


\section{International Journal of Transplantation \& Plastic Surgery}

Reaction During Treatment. Infect Dis Rep 7(4): 6304.

13. Zosso C, Lienhard R, Siegrist HH, Malinverni R, Clerc 0 (2015) Post liposuction infections by rapidly growing mycobacteria. Infect Dis (Lond) 47(2): 69-72.

14. Beeson WH, Slama TG, Beeler RT, Rachel JD, Picerno NA (2001) Group A streptococcal fasciitis after submental tumescent liposuction. Arch Facial Plast Surg 3(4): 277279.
15. Beaudoin AL, Torso L, Richards K, Said M, Van Beneden C, et al. (2014) Invasive group A Streptococcus infections associated with liposuction surgery at outpatient facilities not subject to state or federal regulation. JAMA Intern Med 174(7): 1136-1142.

16. Rhee CA, Smith RJ, Jackson IT (1994) Toxic shock syndrome associated with suction-assisted lipectomy. Aesthetic Plast Surg 18(2): 161-163. 